\title{
Real interest parity in Central and Eastern European countries: evidence on integration into EU and the US markets
}

\begin{abstract}
We investigate the validity of real interest parity (RIP) for the 13 Central and Eastern European countries, over the period 1996-2011. We consider a panel stationarity test that allows for multiple breaks advocated by Carrion-i-Silvestre et al. (2005) and confirmed the strong version of RIP. We found that the events of the last two decades, including the recent global financial crisis affected most of the real interest differential series. Based on the localpersistent model, we found that these countries take less than a year to converge to the RIP value. Financial market integration in these countries is invariant with respect to the reference country - the US and EU.
\end{abstract}

Keyword: Real interest rate parity; Structural breaks; Half-lives 